\title{
Fuzzy Sliding Mode Control of a VAV Air-Conditioning Terminal Temperature System
}

\author{
Fuzhou Niu, ${ }^{1}$ Ziyang Li, ${ }^{2,3}$ Lijian Yang, ${ }^{2,3}$ Zhengtian Wu ${ }^{2},{ }^{2,3}$ Qixin Zhu $\mathbb{D}^{1},{ }^{1}$ \\ and Baoping Jiang ${ }^{2,3}$ \\ ${ }^{1}$ School of Mechanical Engineering, Suzhou University of Science and Technology, Suzhou, China \\ ${ }^{2}$ School of Electronic and Information Engineering, Suzhou University of Science and Technology, Suzhou, China \\ ${ }^{3}$ Suzhou Institute of Smart City, Suzhou University of Science and Technology, Suzhou, China \\ Correspondence should be addressed to ZhengtianWu; wzht8@mail.usts.edu.cn and Qixin Zhu; bob21cn@163.com
}

Received 1 September 2020; Revised 24 October 2020; Accepted 12 December 2020; Published 22 December 2020

Academic Editor: Xue-bo Jin

Copyright ( $\odot 2020$ Fuzhou Niu et al. This is an open access article distributed under the Creative Commons Attribution License, which permits unrestricted use, distribution, and reproduction in any medium, provided the original work is properly cited.

A varied air volume (VAV) air-conditioning system comprises diverse input and/or output disturbances, which are commonly nonlinear, with large lag and uncertainty. Based on the traditional control methods, testing the controlling parameters of a VAV air-conditioning system is challenging. Sliding mode control could improve the robustness of the system due to the adaptive capacity of disturbance rejection. Moreover, the fuzzy algorithm could be employed to determine the stability of a sliding control system by adjusting the parameters in the approach rate, reducing the switching frequency, and weakening chatter. Fuzzy sliding mode control is investigated in this paper to improve the performance of a VAV air-conditioning system. Simulation results verify that the sliding mode control is suitable for a VAV air-conditioning system to achieve good adaptability and robustness considering the influence of multiple external variable disturbances. In addition, the chattering of the system is improved after the introduction of fuzzy control.

\section{Introduction}

A variable air volume air-conditioning system belongs to an all-air air-conditioning system, which can automatically adjust the air supply volume of air conditioning according to the change in air-conditioning load and indoor air parameters. However, appropriate control strategies should be developed to solve the problems caused by the complexity of the control system because of the intricate VAV air-conditioning system terminal equipment and the high requirements for the overall control of the system.

Many scholars have proposed VAV air-conditioning control methods. For example, hysteresis relay feedback control was introduced into the model parameter identification of indoor temperature hysteresis characteristics, thereby providing a new method for the identification of the characteristics of indoor temperature hysteresis in [1]. For indoor fresh air demand, the total fresh air flow is dynamically corrected on the basis of the detected occupancy rate of each area and relevant measurement values using fresh air from the overventilated area [2]. A fault-tolerant control method was proposed in [3] to control the outdoor air circulation and AHU supply air temperature, which are, respectively, related to indoor air quality and humidity, to meet the ASHRAE standard in a VAV system. A neural fuzzy structure of a parameter self-tuning decoupled fuzzy neural PID controller was proposed in [4]. An adaptive neural network-based supply air temperature controller was introduced in [5] for the air handling unit in heating, ventilation, and air-conditioning systems.

The classical PID control equation with a decoupled coefficient was used as the Sugeno function to introduce the following part of the fuzzy rule, which improves the antiinterference capability of the system. However, some problems occur when only fuzzy control in air-conditioning systems is used. The two steps do not have a systematic design method and mainly rely on expert experience and repeated experiments of designers because of the two 
important steps of fuzzy control design: the quantization range of parameters and the design of fuzzy rules. In addition, the design of fuzzy control is not systematic. Therefore, fuzzy control should be combined with some other control strategies in most cases to achieve the desired control effect. Since its emergence in the 1950s, sliding mode control (SMC) has been proven to be an effective control strategy for many nonlinear complex physical systems. SMC has witnessed considerable efforts undertaken in the field of theoretical analysis and SMC application. The following examples are provided. The issue of SMC for stochastic semiMarkovian jump systems was studied in [6,7] with application to space robot manipulators. A sliding mode controller of active magnetic bearing was proposed in [8] to achieve rotor $3 D$ trajectory control. A constraint design with a sliding mode strategy was proposed in [9] to improve the stability of aircraft engine control. A terminal sliding mode controller was designed in [10] to track the planned speed signal, which can timely suppress the adverse dynamic behavior of an electric vehicle after a tire blows out on a highway. A high-speed nonsingular terminal switch SMCl strategy for robots was proposed in [11]. This strategy enhanced the performance of the control system by switching between the sliding mode controllers according to different control requirements in different regions of the state space. A nonsingular terminal SMC algorithm was introduced in [12] to track the body position of a hexapod walking robot stably and accurately. This algorithm provided a reliable method to improve the walking and operating capability of a multilegged walking robot in a special environment. For the real-time tracking and stability of the control system, $[13,14]$ provide a good solution. Considering SMC combined with the fuzzy method, the research results were also rich. For instance, a fuzzy SMC strategy was proposed in [15] to solve the problem of independent control of temperature and humidity in air conditioners. In $[16,17]$, the prediction and dynamic analysis of the data model of the environment detected by the sensor is helpful to the accuracy of airconditioning control. In view of the influence of data noise obtained by air-conditioning sensors on intelligent control, the filter designed in $[18,19]$ can be used to improve the control accuracy of the indoor environment. A novel integral fuzzy SMC for T-S fuzzy systems was also proposed in $[20,21]$ to address the issues of stabilization and dissipation (additional details are provided in [22-24] and references therein).

This study addresses the issue of SMC design for a VAV air-conditioning system. A VAV air-conditioning system with multiinput and multioutput, nonlinearity, large lag, uncertainty, and other characteristics is suitable because of the strong robustness of the SMC to the external disturbance and modeling dynamics of the system and the advantages of order reduction, decoupling, fast response, and easy implementation. However, some problems emerge in the design of SMC, and the most prominent one is chattering. Therefore, this study selects the improved power index approach rate and the parameters of the sliding mode approach rate through fuzzy control to minimize chattering.

\section{VAV Air-Conditioning System Overview and Mathematical Model}

2.1. VAV Air-Conditioning System Structure. The schematic of a VAV air-conditioning system is illustrated in Figure 1. A VAV air-conditioning system mainly comprises five components: air handling unit, air supply pipeline module, indoor air supply terminal, electric control unit, and a common all-air module.

Figure 1 shows the primary VAV return air system. After the indoor return air and outdoor fresh air are mixed, the mixed air is cooled and dehumidified and sent to each room. The air supply volume of the air conditioner is controlled by the air supply sensor and the blower at the end of the air conditioner to achieve the desired indoor temperature.

2.2. Air Supply Volume Controlling of a VAV Air Conditioner. As shown in Figure 2, the total air supply is adjusted by the fan speed and the guide vane valve, which is generally referred to as the fan control. An appropriate coordinated control algorithm should be designed and adopted to balance the fan speed and the room temperature by controlling the total air supply volume. Three common parameters are used to control the fan speed, namely, constant static pressure, variable static pressure, and total air volume control. In a prior study [25], a static pressure reset algorithm was proposed to minimize the static pressure in the air supply duct while maintaining regional comfort. This method is proven to be economical in practice and can reduce fan power consumption in VAV.

As shown in Figure 3, in a VAV air-conditioning system, the set value of the air supply temperature could directly influence the control of indoor temperature. The energy of an air-conditioning system is inefficiently used when the air supply temperature is substantially high. Meanwhile, uniform indoor air supply and minimum fresh air volume are required when the air supply temperature is substantially low. The methods of the set value determination of air supply temperature mainly include trial, error, and voting methods.

\subsection{Room Temperature Control of a VAV Air-Conditioning System. Room temperature controls physical processes in a VAV terminal device, which changes the air supply volume by adjusting the deviation of indoor and desired room temperatures. The terminal of a VAV air-conditioning system can be divided into pressure-dependent and pres- sure-independent terminals according to different control modes. The pressure-independent terminal is adopted in this study because of the poor stability of the pressure-dependent type and serious system coupling. The control strategy is shown in Figure 4. A sliding mode controller is adopted to the room temperature control in this paper.}

2.4. Mathematical Model of Air-Conditioning Room Temperature. The investigated area is an air-conditioned room, which is located in an office building. The temperature of the building is considerably higher in summer and/or 


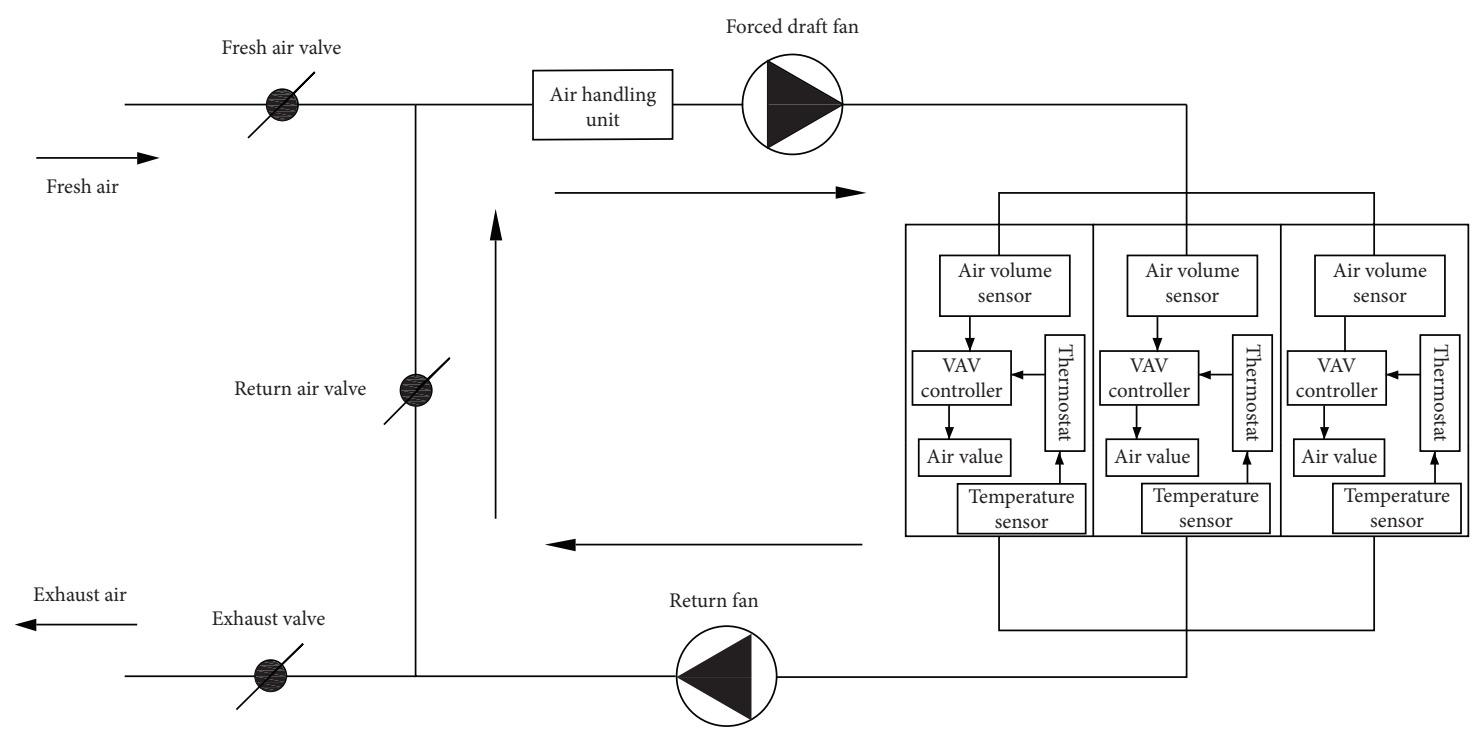

FIgURE 1: Structure diagram of the VAV air-conditioning system.

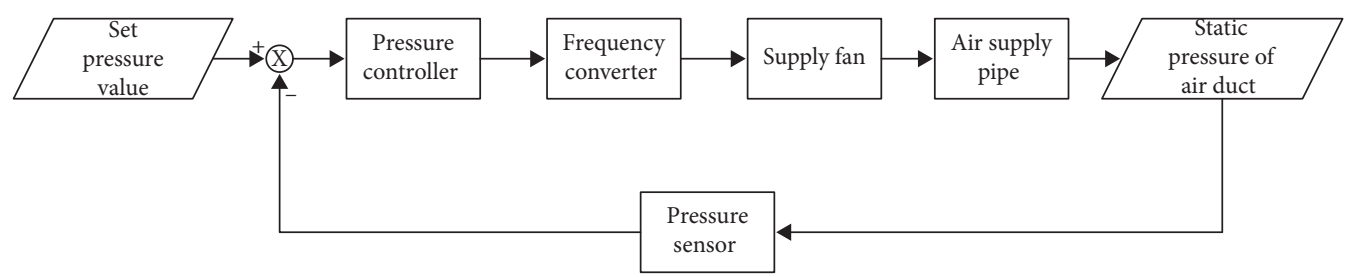

Figure 2: Diagram of the total air volume of a VAV air conditioner control system.

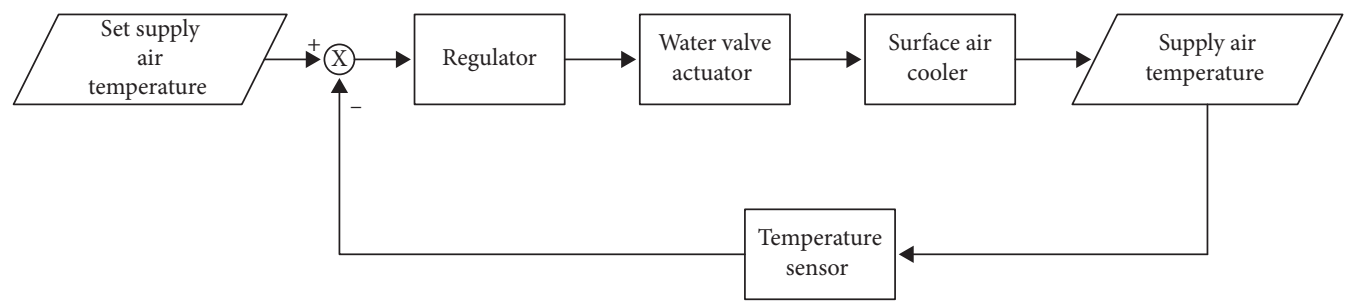

FIGURE 3: Diagram of the air temperature control of a VAV air-conditioning supply.

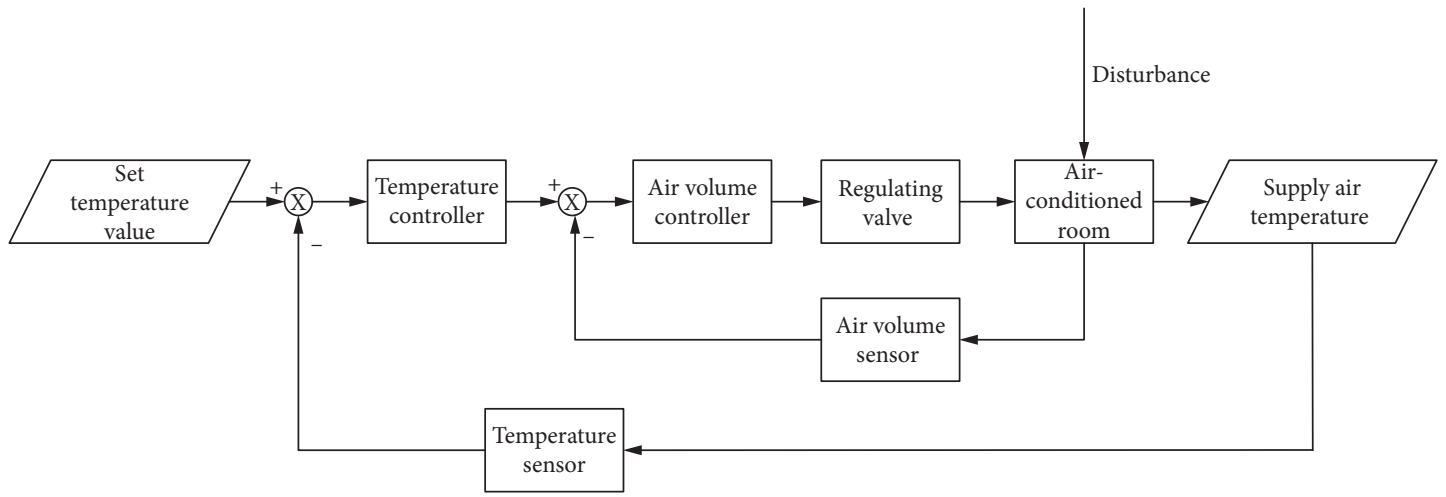

FIgURE 4: Diagram of the room temperature control of a VAV air-conditioning system. 
daytime. The boundary conditions of air-conditioning rooms are affected by many factors, including solar radiation, internal heat dissipation, lighting energy, and radiation of walls and equipment. An accurate mathematical model of such a complex system is unavailable. The following assumptions are assigned to simplify the mathematical model of room temperature.

(1) Temperature is in a uniform distribution status in the air-conditioned room

(2) The air input and output in the air-conditioned room is in a balanced state

(3) The heat storage of enclosures is neglected

(4) Default adjacent rooms have a similar influence on the air-conditioned room

(5) Other parameters, including heat load of indoor equipment and individuals, are defined as indoor heat load interference

Considering these assumptions, the differential equation of the heat balance of the room based on the law of thermodynamics can be obtained as follows:

$$
\rho_{\text {air }} V c_{\text {air }} \frac{\mathrm{d} T}{\mathrm{~d} t}=Q_{r}(t)+Q_{w}(t)+Q_{\mathrm{in}}
$$

where $V$ is the volume of the air-conditioned room, $\mathrm{m}^{3} ; \rho_{\text {air }}$ is the air density, $\mathrm{kg} / \mathrm{m}^{3} ; c_{\text {air }}$ is the specific heat capacity of air, $\mathrm{kJ} /\left(\mathrm{kg} .{ }^{\circ} \mathrm{C}\right) ; \mathrm{T}$ is the temperature of the air-conditioned room, ${ }^{\circ} \mathrm{C} ; \mathrm{Q}_{r}(t)$ is the heat provided by the air conditioner; $Q_{w}(t)$ is the indoor sensible heat; and $Q_{\text {in }}$ is the indoor thermal load interference.

Because the air input and output of the air-conditioned room are in balance. So, $Q_{r}(t)$ is, respectively, expressed as follows:

$$
Q_{r}(t)=G_{s} c_{\text {air }}\left(T_{s}-T\right) .
$$

The heat storage of enclosures is neglected. So, $Q_{w}(t)$ is, respectively, expressed as follows:

$$
Q_{w}(t)=k_{1} F_{1}\left(T_{i}-T\right)+k_{\text {out }} F_{\text {out }}\left(T_{\text {out }}-T\right),
$$

where $G_{s}$ is the air supply volume, $\mathrm{kg} / \mathrm{s} ; T_{s}$ is the air supply temperature, ${ }^{\circ} \mathrm{C} ; k_{1}$ is the heat transfer coefficient of the adjacent room inner wall, $\mathrm{kW} /\left(\mathrm{m}^{2} \cdot{ }^{\circ} \mathrm{C}\right) ; F_{1}$ is the heat transfer area of the adjacent room inner wall, $\mathrm{m}^{2} ; k_{\text {out }}$ is the heat transfer coefficient of the external wall, $\mathrm{kW} /\left(\mathrm{m}^{2}{ }^{\circ} \mathrm{C}\right) ; F_{\text {out }}$ is the heat transfer area of the external wall, $\mathrm{m}^{2} ; T_{\text {out }}$ is the outdoor ambient temperature, ${ }^{\circ} \mathrm{C}$; and $Q_{\text {in }}$ is the indoor heat load, kW.

\section{Design of the Fuzzy Sliding Mode Controller}

\subsection{Design of the Sliding Mode Controller}

3.1.1. Selection and Design of the Sliding Surface and Approach Rate. An integral sliding surface can smoothen the torque, reduce the steady-state error of a system, weaken the chattering, and enhance the stability of a controller. The integral sliding surface can be expressed as follows:

$$
s=e+k_{s} \int_{0}^{t} e \mathrm{~d} t
$$

where $e$ is the deviation of actual and desired room temperatures; $e=T-T_{d}$, where $T$ and $T_{d}$ are the actual and desired temperatures of the air-conditioned room, respectively.

The exponential approach rate $\dot{s}=-\varepsilon \operatorname{sgn}(s)-k s$ is a typical approach rate, which can gradually reduce the approach speed from a large value to zero through the exponential approach term and help the moving point reach the switching surface at a low speed. However, if the constant $k$ is increased, then the convergence rate is accelerated, but the chattering in the sliding mode stage is strengthened; if the constant $\varepsilon$ is reduced, then the chattering in the sliding mode stage is weakened, but the convergence rate in the motion stage is slow. The general index approach rate is usually a compromise method to determine the constant but does not efficiently solves this problem [26].

The improved power exponential approach rate is selected to overcome the shortcomings of the exponential approach rate [27]:

$$
\dot{s}=-\varepsilon|s|^{\alpha} \operatorname{sgn}(s)-k s^{\beta},
$$

where $\varepsilon>0,0 \leq \alpha<, k \geq 0$, and $\beta$ is a positive odd number.

Given that $\lim _{s \longrightarrow 0^{+}} \dot{s}=\lim _{s \longrightarrow 0^{+}}-\varepsilon|s|^{a} \operatorname{sgn}(\mathrm{s})-k s^{\beta}<0$ and $\lim _{s \longrightarrow 0^{-}} \dot{s}=\lim _{s \longrightarrow 0^{-}}-\varepsilon|s|^{a} \operatorname{sgn}(\mathrm{s})-k s^{\beta}>0$, the power reaching law guarantees the existence of the sliding mode and the global arrival condition. In particular, when $\alpha=0$ and $\beta=1$, the above formula is the exponential approach rate; when $k=0$, the above formula is the power approach rate.

When the moving point is far from the sliding mode switching surface, that is, when $|s| \geq 1, \varepsilon|s|^{\alpha} \geq \varepsilon$, and $k s^{\beta} \geq k$, the improved power index approach rate has a faster approach speed than the general index approach rate. When the moving point is close to the sliding mode surface, that is, when $|s|<1, \varepsilon|s|^{\alpha} \leq \varepsilon$, and $k s^{\beta} \leq k s$, the approach speed slows down, and the chattering weakens.

3.1.2. Calculation of Control Rate. Through simultaneous formulas (1)-(3) and setting $Q_{r}(t)$ to $u$, the differential equation of the temperature of an air-conditioned room can be obtained as follows:

$\rho_{\text {air }} V c_{\text {air }} \frac{\mathrm{d} T}{\mathrm{~d} t}=u+k_{1} F_{1}\left(T_{i}-T\right)+k_{\text {out }} F_{\text {out }}\left(T_{\text {out }}-T\right)+Q_{\text {in }}$.

The derivation of formula (4) can then be organized as follows:

$$
\begin{gathered}
\dot{s}=\dot{e}+k_{s} e=\frac{1}{\rho_{\text {air }} V c_{\text {air }}}\left(u+k_{1} F_{1}\left(T_{i}-T\right)\right. \\
\left.+k_{\text {out }} F_{\text {out }}\left(T_{\text {out }}-T\right)+Q_{\text {in }}\right)+k_{s} e .
\end{gathered}
$$


The convergence rate of the improved power index shown in simultaneous formula (5) can be further expressed as follows:

$$
\begin{gathered}
\frac{1}{\rho_{\text {air }} V c_{\text {air }}} *\left(u+k_{1} F_{1}\left(T_{i}-T\right)+k_{\text {out }} F_{\text {out }}\left(T_{\text {out }}-T\right)+Q_{\text {in }}\right) \\
+k_{s} e=-\varepsilon|s|^{\alpha} \operatorname{sgn}(s)-k s^{\beta} .
\end{gathered}
$$

In order to solve the problem of sensor measurement noise in sliding mode control, the noise of temperature measured by an air-conditioning sensor is generally unknown but bounded, and compared with the measured temperature, the noise is small, so the stability of the system can be guaranteed in the case of ignoring the noise. Therefore, the SMC law based on the improved power exponential approach law can be calculated as follows:

$$
\begin{aligned}
u= & \rho_{\text {air }} V c_{\text {air }}\left(-\varepsilon|s|^{\alpha} \operatorname{sgn}(s)-k s^{\beta}-k_{s} e\right)-k_{1} F_{1}\left(T_{i}-T\right) \\
& -k_{\text {out }} F_{\text {out }}\left(T_{\text {out }}-T\right)-Q_{\text {in }} .
\end{aligned}
$$

A defined Lyapunov function is provided as follows to prove the stability of the system:

$$
\begin{aligned}
v= & \frac{1}{2} s^{2}, \\
\dot{V}(s)= & \dot{s} s=\left(\dot{e}+k_{s} e\right) s \\
= & \left(\frac{1}{\rho_{\text {air }} V c_{\text {air }}} \times\left(u+k_{1} F_{1}\left(T_{i}-T\right)\right.\right. \\
& \left.\left.+k_{\text {out }} F_{\text {out }}\left(T_{\text {out }}-T\right)+Q_{\text {in }}\right)+k_{s} e\right) s .
\end{aligned}
$$

$\dot{V}(s)=-\varepsilon s|s|^{\alpha} \operatorname{sgn}(s)-k s^{\beta+1}$ can be obtained by integrating equation (9) into the above equation. The limitation of the approach rate parameters indicates that the value range of each parameter is $\varepsilon>0,0 \leq \alpha<1, k \geq 0$, and $\beta$ is the positive odd. Therefore, $\dot{V}(s)<0$, and the system is asymptotically stable.

\subsection{Design of the Fuzzy Switching Surface}

3.2.1. Fuzziness of Approach Rate Parameters. An improved power index approach rate, which can reduce the chattering to a certain extent, is selected in this study. A one-dimensional fuzzy controller is proposed in this paper to improve the air-conditioning system and enhances its robustness in the operation process and ensures that the system can quickly access the sliding mode state while suppressing chattering. The comparison between sliding mode controllers without/with the fuzzy controller is investigated through simulation using the Matlab interface.

The input signal of the fuzzy adaptive sliding mode controller is the temperature error $e$, and the output signal is the approach law parameters $\varepsilon$ and $k$. The fuzzy subsets of input variables are negative big, negative middle, negative small, invariant, positive small, positive middle, positive big\}, which can be shorted as $\{\mathrm{NB}, \mathrm{NM}, \mathrm{NS}, \mathrm{Z}, \mathrm{PS}, \mathrm{PM}, \mathrm{PB}\}$, respectively. The fuzzy subsets of output variables are $\{\mathrm{NB}$, $\mathrm{NS}, \mathrm{Z}, \mathrm{PS}, \mathrm{PB}$. The input quantization is in the $(-1,15)$ region, the output $\varepsilon$ quantization is in the $(0.003,0.03)$ region, and the $k$ quantization is in the $(5,40)$ region.

The entire fuzzy SMC process is shown in Figure 5.

3.2.2. Membership Function and Fuzzy Rules. The membership function is selected as a triangle membership function. Equal values are assigned to the fuzzy subset. The membership functions of the input and output signals are shown in Figures 6-8.

According to the actual control effect, the fuzzy control rules of the approach rate parameters $\varepsilon$ and $k$ are shown in Table 1.

According to the above fuzzy rules, when the deviation signal $e$ is large, the fuzzy control system selects large $\varepsilon$ and $k$ to ensure that the system can approach the sliding surface at a fast speed. When $e$ is small, the fuzzy control system selects small $\varepsilon$ and $k$ to reduce the approach speed and weaken system chattering [28].

3.2.3. Fuzzy Reasoning. The fuzzy controller in this study is built with the fuzzy module of MATLAB, and the center of gravity method is used to solve the fuzzy problem:

$$
\begin{aligned}
& \varepsilon=\frac{\int \varepsilon u_{\varepsilon}(\varepsilon) \mathrm{d} \varepsilon}{\int u_{\varepsilon}(\varepsilon) \mathrm{d} \varepsilon}, \\
& k=\frac{\int k u_{k}(k) \mathrm{d} k}{\int u_{k}(k) \mathrm{d} k},
\end{aligned}
$$

where $u_{\varepsilon}(\varepsilon)$ and $u_{k}(k)$ are the corresponding membership functions.

\section{Simulation Analysis}

4.1. Design of a Simulation Model. The air-conditioned room is $5 \mathrm{~m}$ long, $4 \mathrm{~m}$ wide, and $3 \mathrm{~m}$ high. The initial temperature in the room is $30^{\circ} \mathrm{C}$, and the air supply temperature is $16^{\circ} \mathrm{C}$. The temperature change curve is assumed to between 7:00 and 19:00 in the building area [29], and the temperature change curves of the next room in the air-conditioned room are as shown in Figure 9.

Considering that the air-conditioned room belongs to the office building [14], the following assumptions for the heat load caused by the change in indoor personnel and the operation of computers and other equipment are presented as shown in Figure 10.

4.2. Influence of Approach Rate Parameters on the Control Effect. When $\varepsilon$ and $k$ are, respectively, set to 0.1 and 5, chattering is evident after the system reaches stability despite the fast response speed. When $\varepsilon$ and $k$ are, respectively, set to 0.001 and 5 , the transition time increases despite the reduction in chattering as shown in Figure 11. 


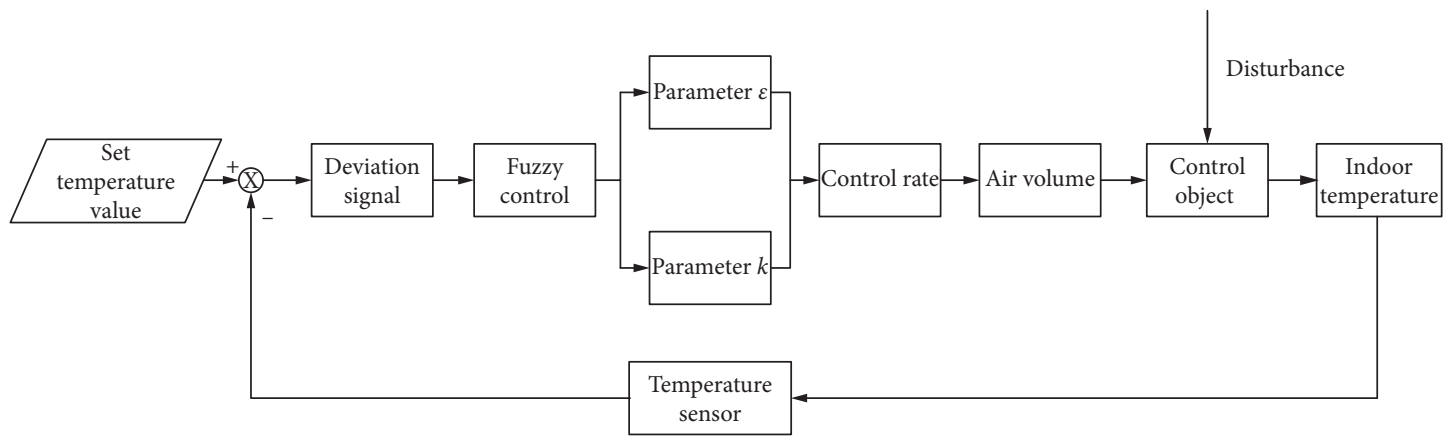

Figure 5: Flow chart of fuzzy SMC.

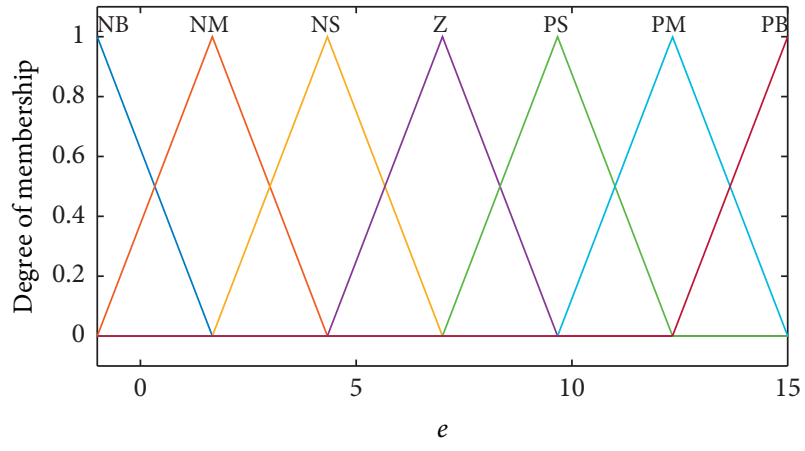

Figure 6: Membership function of temperature error $e$.

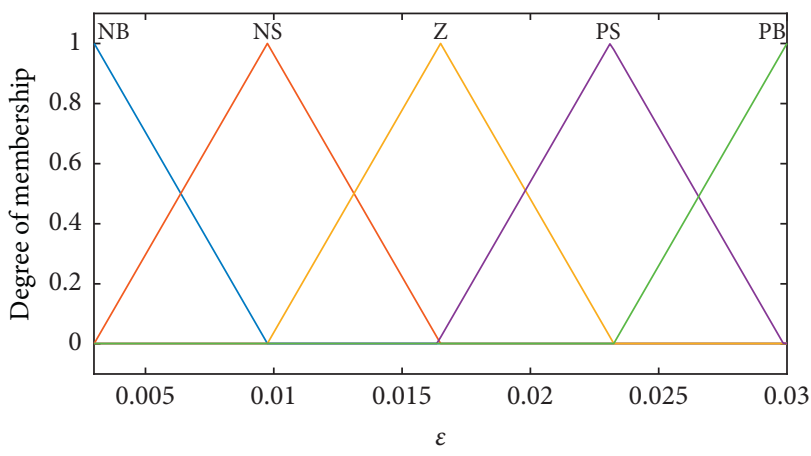

Figure 7: Membership function of approach law parameter $\varepsilon$.

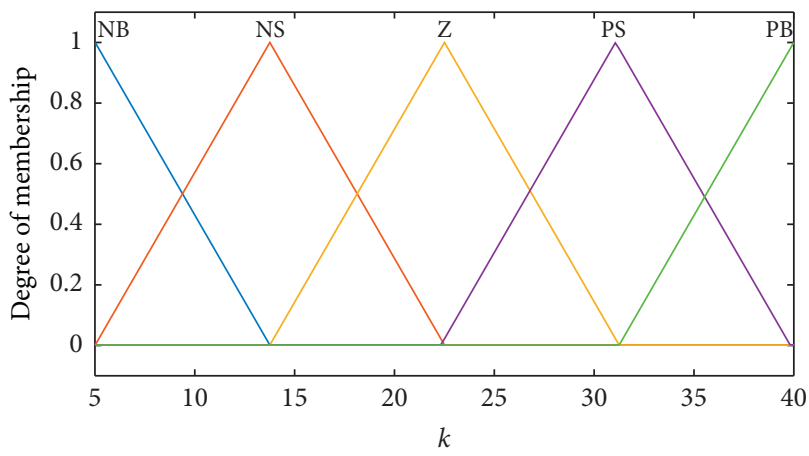

FIGURE 8: Membership function of approach law parameter $k$.
TABle 1: Fuzzy control rule table of parameters $\varepsilon$ and $k$.

\begin{tabular}{llllllll}
\hline$e$ & NB & NM & NS & Z & PS & PM & PB \\
$\varepsilon$ & NB & NS & PS & PB & PB & PB & PB \\
$k$ & NB & Z & PS & PB & PB & PB & PB \\
\hline
\end{tabular}

4.3. Simulation Model and Results of the Fuzzy Sliding Mode Controller. When the fuzzy controller designed in Section 4.2 is used, the temperature response curve from 7:00 to 19:00 is presented as Figure 12. The system is robust when the external variables are substantially disturbed.

The temperature response curve of the fuzzy SMC is compared with the curve under the conditions of $\varepsilon=0.1$ and $k=5$. After the introduction of the fuzzy control, the system not only has a shorter transition time than the case of $\varepsilon=0.1$ and $k=5$ but also has a small steady-state static difference. Moreover, fuzzy control can suppress chattering and improve the dynamic and steady performance of the system. According to the response characteristics of room temperature under variable air volume regulation, the delayed response curves of room temperature under three methods are obtained through simulation experiments. And the experiments show that in the process of variable air volume adjustment, the delay caused by the delay of the end air volume to the fan speed and the air valve opening adjustment response is much smaller than the response delay of the room temperature to the room air volume change as shown in Figure 13.

The air supply volume of air-conditioned rooms changes with indoor and outdoor heat loads. The air supply volume of the system at $7: 00-19: 00$ is presented in Figure 14 .

Considering the running speed of the air conditioner fan, a servo system, in which the air temperature supply changes with the temperature deviation signal $e$, is designed to reduce the energy consumption of the fan. The input signal of the fuzzy controller is the temperature error $e$, and the output signal is supply air temperature Ts. The fuzzy subsets of input and output variables are $\{\mathrm{NB}, \mathrm{NM}, \mathrm{NS}, \mathrm{Z}$, $\mathrm{PS}, \mathrm{PM}, \mathrm{PB}\}$. The input quantization is in the $(0,10)$ region, and the output Ts quantization is in the $(10,16)$ region. The fuzzy control rules are shown in Table 2.

The simulation results are shown in Figure 15. When the fan speed drops, the power consumption of the fan and the noise generated during its operation can be reduced, thereby providing a comfortable and quiet office environment for users. 


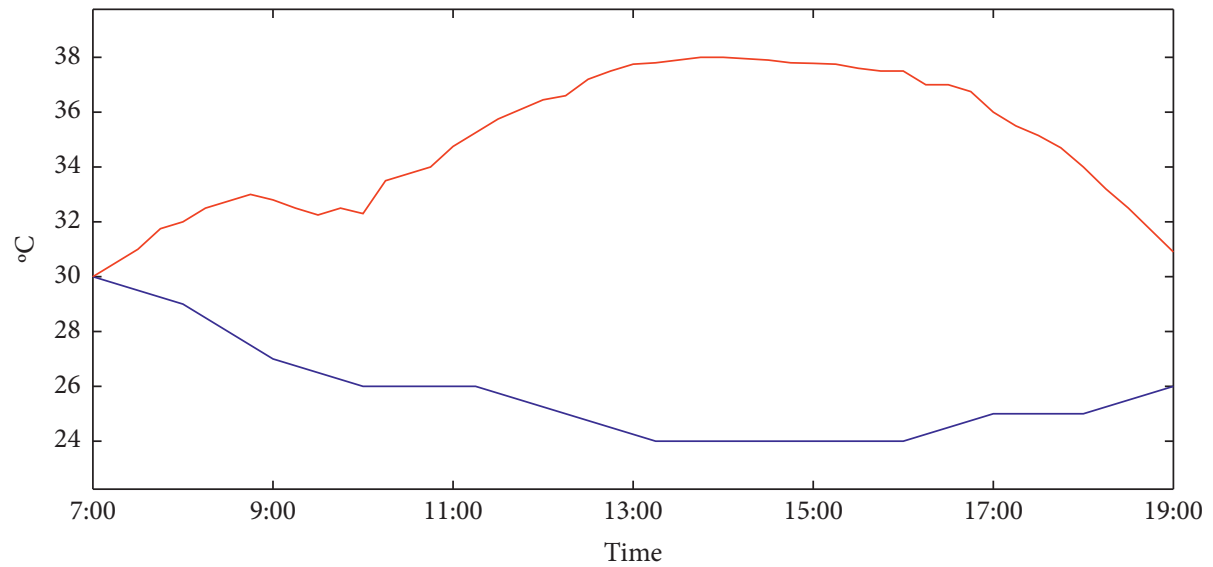

Temperature of adjacent rooms

Outdoor temperature

FIGURE 9: Outdoor temperature and temperature change of the next room.

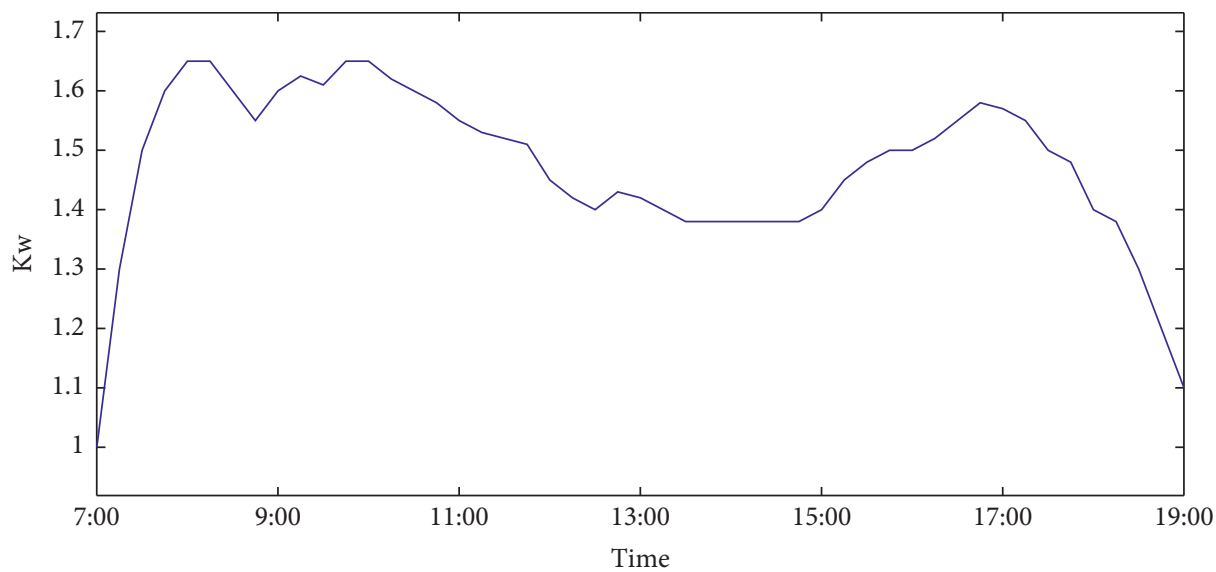

FIgURE 10: Indoor thermal load interference.

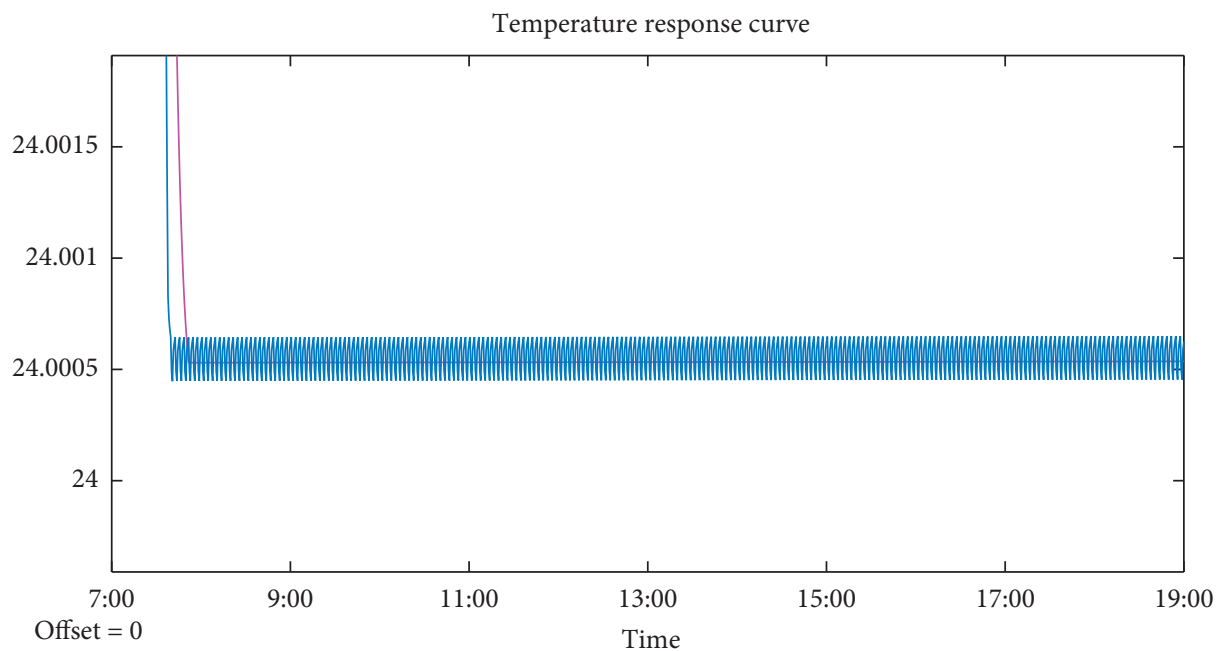

$\mathcal{\varepsilon}=0.01, k=10$

$-\varepsilon=0.1, k=10$

FIGURE 11: Temperature response curve with $\varepsilon=0.1, k=10$ and $\varepsilon=0.001, k=10$. 


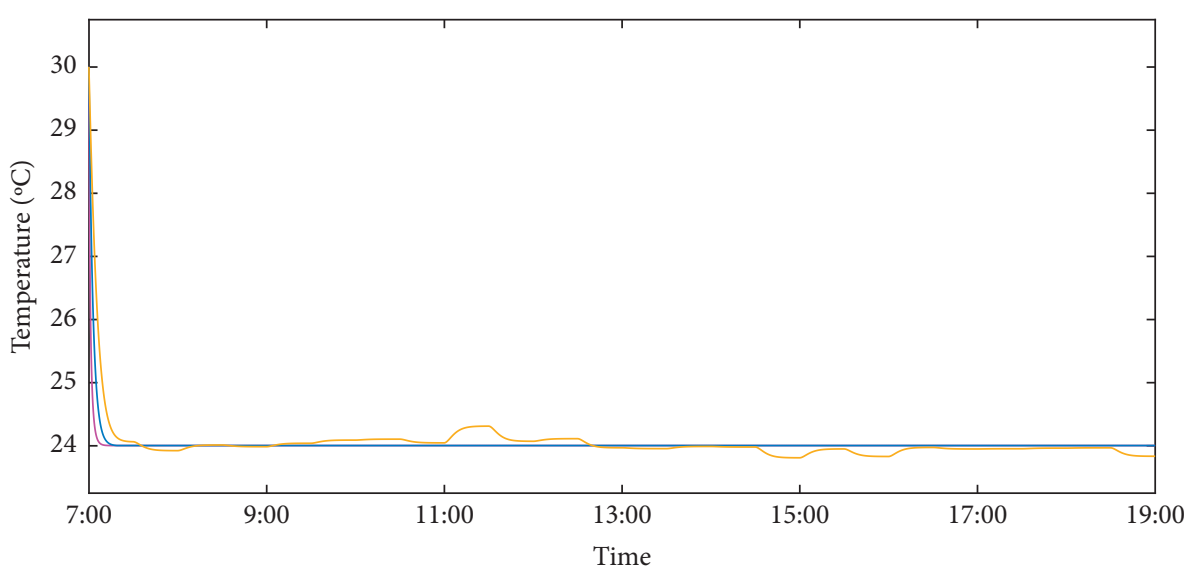

- Fuzzy SMC

$-\varepsilon=0.1, k=5$

PID

FIGURE 12: Temperature response curve comparison.

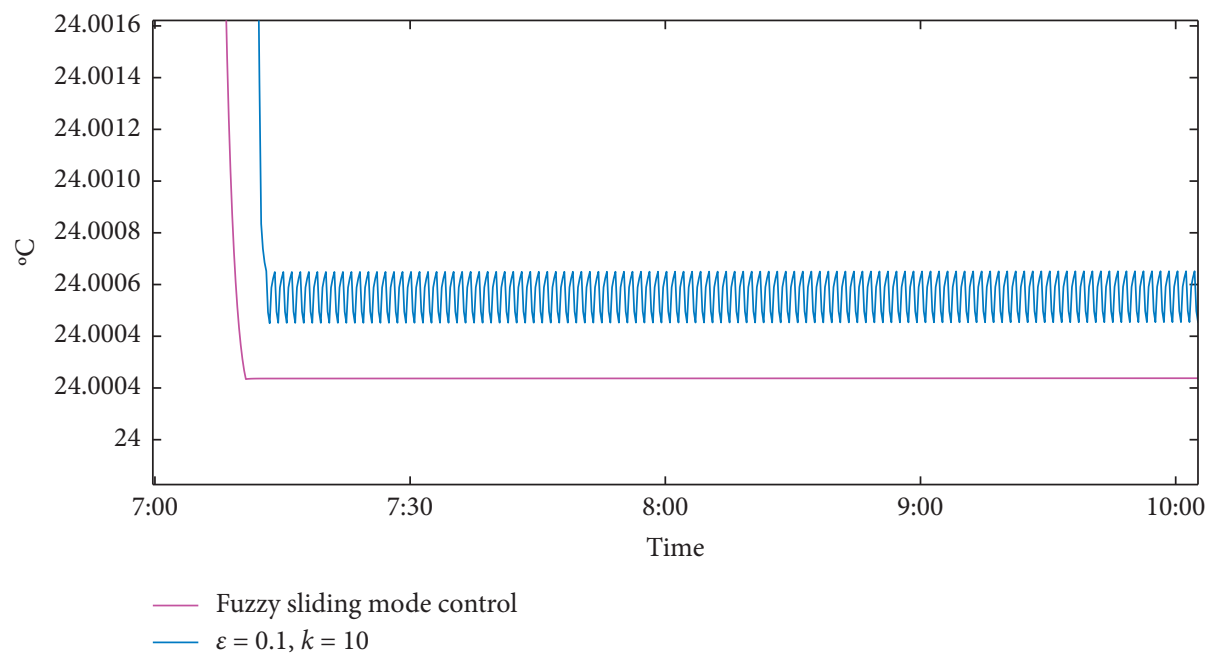

Figure 13: Local temperature response curve after fuzzy control.

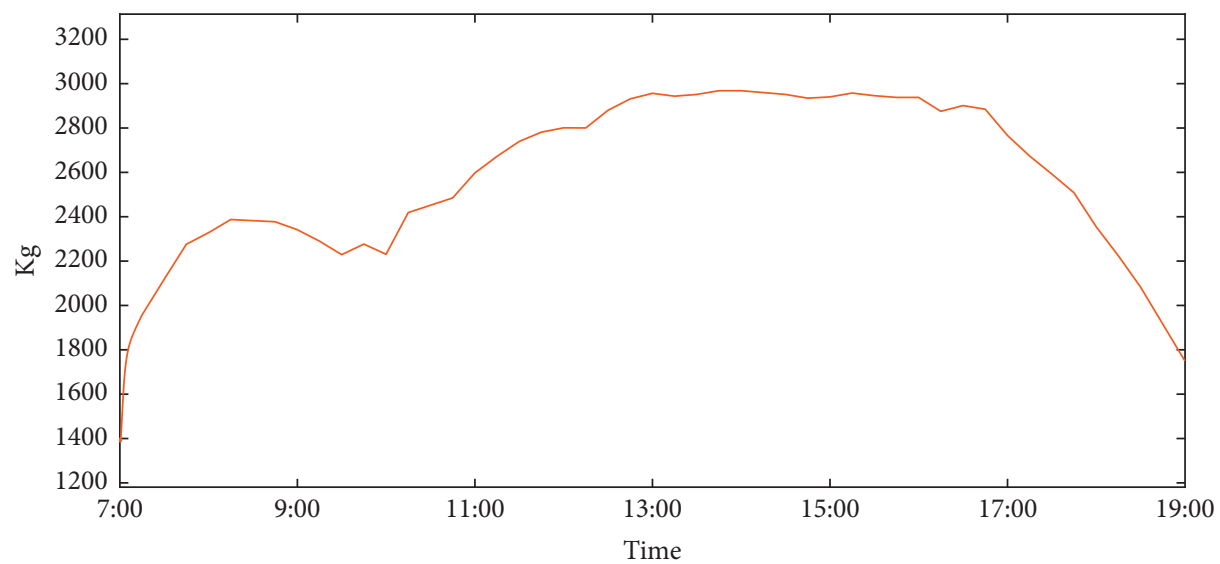

FIGURE 14: Change in the air supply volume of the system. 
TABLE 2: Fuzzy control rule table of supply air temperature Ts.

\begin{tabular}{llccccc}
\hline$e$ & NB & NM & NS & Z & PS & PM \\
Ts & PB & PS & Z & NS & PB & NB \\
\hline
\end{tabular}

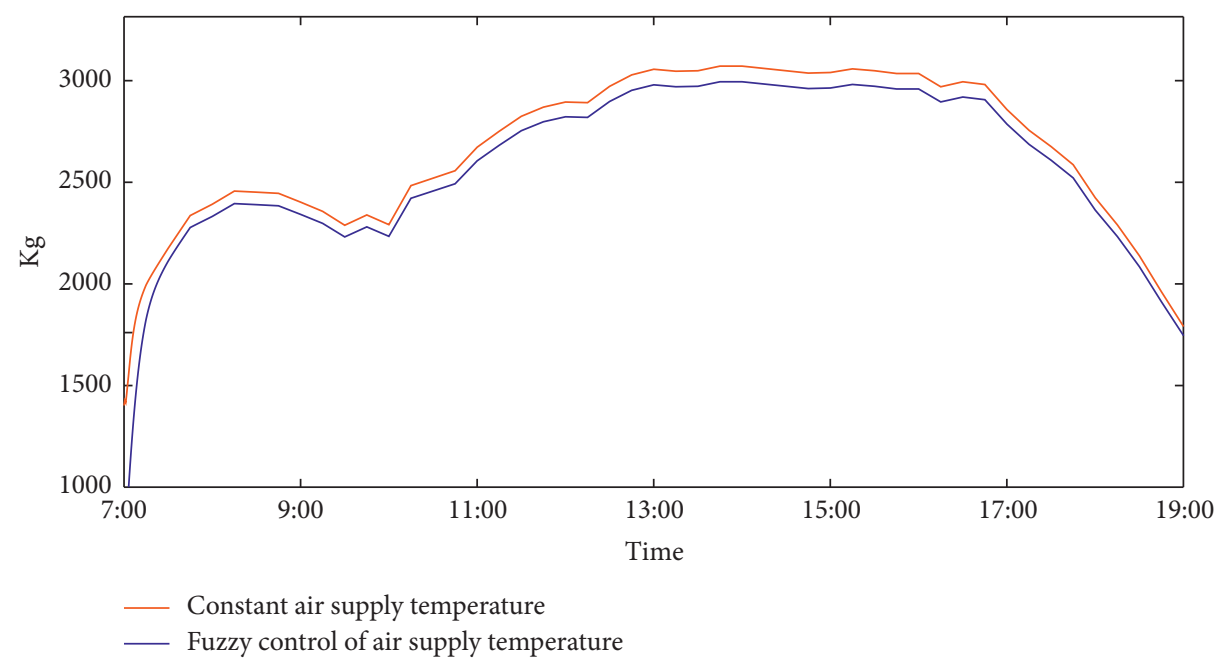

FIgURE 15: Comparison of air supply volume of the system.

\section{Conclusion}

Fuzzy SMC has a strong adaptive ability to the disturbance of systems and parameters. As such, applying it to an airconditioning system with a high uncertainty can overcome the limitations of some traditional control methods and improve the overall stability of the system. In this study, the temperature model of an air-conditioned room is established on the basis of the characteristics of VAV air-conditioning, an SMC is used to regulate air volume, and the temperature is successfully controlled. Moreover, a fuzzy controller is designed in accordance with fuzzy theory to soften the SMC rate, effectively suppress the chattering of the system, and improve its dynamic performance.

\section{Data Availability}

The data in this study are measured by the author. The data used to support the findings of this study are available from the corresponding author upon request.

\section{Conflicts of Interest}

The authors declare that they have no conflicts of interest.

\section{Authors' Contributions}

Fuzhou Niu and Ziyang Li contributed equally to this work.

\section{Acknowledgments}

The authors confirm that all contributors to this research are listed. This work was partly supported by the NSFC (Grant nos. 61803279, 62003231, 11871366, and 61672371), the Qing Lan Project of Jiangsu, the High-Level Innovation and
Entrepreneurship Talents Introduction Program of Jiangsu Province, the Open Project Funding from Anhui Province Key Laboratory of Intelligent Building and Building Energy Saving, Anhui Jianzhu University (Grant no. IBBE2018KX02ZD), the Natural Science Foundation of the Jiangsu Higher Education Institutions of China (Grant no. 18KJB460026), the Suzhou Science and Technology Foundation (Grant no. SYG201813), the Natural Science Foundation of Jiangsu Province (Grant nos. BK20170342 and BK20200989), and Jiangsu Province Graduate Practice Innovation Program (Grant no. SJCX19_0844).

\section{References}

[1] X. Li, S. Lin, J. Zhang, and T. Zhao, "Model parameter identification of indoor temperature lag characteristic based on hysteresis relay feedback control in VAV systems," Journal of Building Engineering, vol. 25, Article ID 100839, 2019.

[2] X. Xu, S. Wang, Z. Sun, and X. Fu, "A model-based optimal ventilation control strategy of multi-zone VAV air-conditioning systems," Applied Thermal Engineering, vol. 29, no. 1, pp. 91-104, 2008.

[3] X. Jin and Z. Du, "Fault tolerant control of outdoor air and AHU supply air temperature in VAV air-conditioning systems using PCA method," Applied Thermal Engineering, vol. 26, no. 11-12, pp. 1226-1237, 2005.

[4] I. Ganchev, A. Taneva, K. Kutryanski, and M. Petrov, "Decoupling fuzzy-neural temperature and humidity control in HVAC systems," IFAC PapersOnLine, vol. 52, no. 25, pp. 299-304, 2019.

[5] J. Zhu, Q. Yang, J. Lu, B. Zheng, and C. Yan, “An adaptive artificial neural network-based supply air temperature controller for air handling unit," Transactions of the Institute of Measurement and Control, vol. 37, no. 9, pp. 1118-1126, 2015.

[6] W. Qi, G. Zong, and H. Karimi, "Sliding mode control for nonlinear stochastic singular semi-Markov jump systems," 
IEEE Transactions on Automatic Control, vol. 65, no. 1, pp. 361-368, 2019.

[7] W. Qi, G. Zong, and H. Karimi, "Sliding mode control for nonlinear stochastic semi-Markov switching systems with application to SRMM," IEEE Transactions on Industrial Electronics, vol. 67, no. 5, pp. 3955-3966, 2019.

[8] X. Yao and Z. Chen, "Sliding mode control with deep learning method for rotor trajectory control of active magnetic bearing system," Transactions of the Institute of Measurement and Control, vol. 41, no. 5, pp. 1383-1394, 2019.

[9] S.-B. Yang, X. Wang, H.-N. Wang, and Y.-G. Li, "Sliding mode control with system constraints for aircraft engines," ISA Transactions, vol. 98, pp. 1-10, 2020.

[10] Y. Lu, M. Yue, Y. Liu, and L. Guo, "RBFNN based terminal sliding mode adaptive control for electric ground vehicles after tire blowout on expressway," Applied Soft Computing Journal, vol. 92, Article ID 106304, 2020.

[11] F. Zhang, "High-speed nonsingular terminal switched sliding mode control of robot manipulators," IEEE/CAA Journal of Automatica Sinica, vol. 4, no. 4, pp. 775-781, 2017.

[12] G. Chen, B. Jin, and Y. Chen, "Accurate and robust body position trajectory tracking of six-legged walking robots with nonsingular terminal sliding mode control method," Applied Mathematical Modelling, vol. 77, no. 2, pp. 1348-1372, 2020.

[13] X. Jin, X. Lian, T. Su, Y. Shi, and B. Miao, "Closed-loop estimation for randomly sampled measurements in target tracking system," Mathematical Problems in Engineering, vol. 2014, Article ID 315908, 12 pages, 2014.

[14] R. Wang, Y. Li, H. Sun, Y. Zhang, and Y. Sun, "Performance analysis of switched control systems under common-source digital upsets modeled by MDHMM," Complexity, vol. 2018, Article ID 4329053, 12 pages, 2018.

[15] L. Yang, Z. Li, Z. Wu, M. Xie, B. Jiang, and B. Fu, "Independent control of temperature and humidity in air conditioners by using fuzzy sliding mode approach," Complexity, vol. 2020, Article ID 1976584, 12 pages, 2020.

[16] B. Knüsel, C. Baumberger, M. Zumwald, D. N. Bresch, and R. Knutti, "Argument-based assessment of predictive uncertainty of data-driven environmental models," Environmental Modelling \& Software, vol. 134, Article ID 104754, 2020.

[17] Y.-T. Bai, X.-B. Jin, X.-Y. Wang, X.-K. Wang, and J.-P. Xu, "Dynamic correlation analysis method of air pollutants in spatio-temporal analysis," International Journal of Environmental Research and Public Health, vol. 17, no. 1, p. 360, 2020.

[18] B. P. Epps and E. M. Krivitzky, "Singular value decomposition of noisy data: noise filtering," Experiments in Fluids, vol. 60, no. $8,2019$.

[19] L. Liu, H. Liu, F. Ding, A. Alsaedi, and T. Hayat, "Data filtering based maximum likelihood gradient estimation algorithms for a multivariate equation-error system with ARMA noise," Journal of the Franklin Institute, vol. 357, no. 9, pp. 5640-5662, 2020.

[20] B. Jiang, H. R. Karimi, Y. Kao, and C. Gao, "A novel robust fuzzy integral sliding mode control for nonlinear semiMarkovian jump T-S fuzzy systems," IEEE Transactions on Fuzzy Systems, vol. 26, no. 6, pp. 3594-3604, 2018.

[21] Y. Wang, H. Shen, H. Reza Karimi, and D. Duan, "Dissipativity-based fuzzy integral sliding mode control of continuous-time TS fuzzy systems," IEEE Transactions on Fuzzy Systems, vol. 26, no. 3, pp. 1164-1176, 2017.

[22] B. Jiang, H. Reza Karimi, Y. Kao, and C. Gao, "Takagi-Sugeno model based event-triggered fuzzy sliding-mode control of networked control systems with semi-markovian switchings,"
IEEE Transactions on Fuzzy Systems, vol. 28, no. 4, pp. 673683, 2019.

[23] B. Jiang, H. Reza Karimi, S. Yang, Y. Kao, and C. Gao, "Takagi-Sugeno model-based reliable sliding mode control of descriptor systems with semi-Markov parameters: average dwell time approach," IEEE Transactions on Systems, Man, and Cybernetics: Systems, 2019.

[24] A. Rebai and K. Guesmi, "Robust adaptive fuzzy sliding mode controller for nonlinear uncertain hysteretic systems," Transactions of the Institute of Measurement and Control, vol. 42, no. 13, Article ID 014233122092102, 2020.

[25] T. Ahmed and P. Kevin Hallinan, "Statistically informed static pressure control in multiple-zone VAV systems," Energy \& Buildings, vol. 135, pp. 244-252, 2017.

[26] B. Taran and A. Pirmohammadi, "Designing an optimal fuzzy sliding mode control for a two-link robot," Journal of the Brazilian Society of Mechanical Sciences and Engineering, vol. 42, no. 1, pp. 1-12, 2020.

[27] H. Tian, S. Xie, Z. Miao, L. Wang, and L. Ren, "Fuzzy sliding mode controller for aeroengine based on an improved power exponential reaching law," Fire Control \& Command Control, vol. 41, no. 2, pp. 108-112, 2016.

[28] A.-H. Attia, S. F. Rezeka, and A. M. Saleh, "Fuzzy logic control of air-conditioning system in residential buildings," Alexandria Engineering Journal, vol. 54, no. 3, pp. 395-403, 2015.

[29] C. Liang, X. Li, X. Shao, and B. Li, "Direct relationship between the system cooling load and indoor heat gain in a nonuniform indoor environment," Energy, vol. 191, Article ID 116490, 2020. 